\title{
The potential impact of public health interventions in preventing kidney disease
}

Rohina Joshi MBBS, MPH, $\mathrm{PhD}^{1}$, Oommen John MBBS, $\mathrm{MD}^{2}$, Vivekanand Jha MD, DM FRCP,

FAMS, $^{3}$

${ }^{1}$ Senior Research Fellow, The George Institute for Global Health, Sydney, Australia; Associate Professor, Sydney Medical School, University of Sydney

${ }^{2}$ Senior Research Fellow, The George Institute for Global Health India, New Delhi, India

${ }^{3}$ Executive Director, The George Institute for Global Health India, New Delhi, India and Professor of Nephrology, University of Oxford, Oxford, UK

Correspondence to: Prof Vivekanand Jha, George Institute for Global Health, 219-221 Splendor Forum, Jasola District Center, New Delhi 110 025, INDIA Email: vjha@pginephro.org 


\section{Abstract}

The years of life lost and years lived with disability due to chronic kidney disease (CKD) increased globally by $90 \%$ and $49.5 \%$ respectively between 1990 and 2013 . In additional to the traditional factors, infections, low birthweight, environmental factors and low socioeconomic status contribute to CKD burden in low and middle income countries (LMIC). System level challenges such as poor appreciation of the burden, insufficient human resources, high healthcare cost, poor referral pathways, inaccurate health information systems and inadequate medicine supply pose barriers to CKD control. In this paper, we present evidence that CKD burden in LMIC are related to system-wide issues, which can be effectively reduced using innovative, affordable and scalable interventions. A multipronged approach, such as improving socio-economic determinants of health, enabling environment for healthy decision-making, and sustainable interventions. Innovative approaches at primary level include promoting healthy behaviours, counselling and education in primary care, tasksharing between physicians and non-physician health providers, using technology to train non-physicians to screen, diagnose, refer, follow-up and educate patients and ensuring quality. Stronger political will and system level change are needed to prevent and manage CKD if the sustainable development goals of reducing pre-mature mortality from NCDs by 2030 are to be attained. 


\section{Background}

Demographic, population and disease transitions have led to a large increase in the kidney disease burden globally. In high income countries (HIC), chronic kidney disease (CKD) is linked to the prevalent non-communicable diseases (NCD) like diabetes and hypertension, whereas acute kidney injury (AKI) is encountered largely amongst hospitalised patients, usually in intensive care units.

On the other hand, the pattern of kidney diseases in low and low middle income countries (LMIC) is reflective of a dual disease burden with contributions both from persisting and emerging infections and oncoming lifestyle-related diseases. Preventable AKI due to inadequate sanitation, lack of safe drinking water, inadequately treated infections, and suboptimal care during pregnancy and delivery continue to be encountered. At the same time, rapid changes in lifestyle and diet, and an ageing population are fuelling the burgeoning CKD epidemic. Infections also contribute to CKD burden, either by causing direct progressive renal injury as with human immunodeficiency virus (HIV), and hepatitis B and C infections; or by causing AKI (e.g. malaria, hemorrhagic fever, dengue, leptospirosis etc), which either increase the future risk of CKD or worsen the progression and outcomes in those with preexisting CKD.

Healthcare systems in LMIC also exhibit several deficiencies, such as a mismatch between the disease burden and care provision, particularly at the primary care level - manifested as shortage and maldistribution of physicians, lack of systematic prevention and control programs and reliance on unproven therapies including indigenous medical systems. All of these contribute to development and/or progression of kidney disease. Insufficient allocation 
of healthcare funds and unstructured care models create additional fault lines. People do not seek care until late in the disease process, by which time expensive curative treatment becomes necessary, as opposed to cost-effective primary and secondary preventive measures. A large proportion present with advanced kidney failure and need hospitalization and urgent dialysis. Other factors that increase morbidity, mortality and cost of care are nonstandard care delivery - for example irregular hemodialysis frequency, unregulated dialysis reuse, and reliance on poor quality generics and biosimilars.

Shoolwerth et al. suggested that a health condition should be recognized as a public health problem when it places a large and increasing burden on society, disproportionately affects disadvantaged segments of the population, is amenable to preventive strategies, but they are not yet in place $^{1}$. In this paper, we present evidence that the kidney disease burden in LMIC is substantially related to system-wide issues and can be effectively reduced using public health interventions (PHI), describe the levels of $\mathrm{PHI}$ with implications for kidney health, the use of innovations in public health delivery to develop affordable and scalable models to reduce disease burden and improve outcomes, and discuss examples of such interventions.

\section{The burden of chronic kidney disease}

Kidney diseases, both acute and chronic, are important causes of morbidity and premature mortality. Population-based surveys suggest about $8-10 \%$ community-wide prevalence of CKD. A recent analysis revealed a higher age-standardized prevalence of CKD amongst adults in LMIC (10.6\% in men and $12.5 \%$ in women) than HIC ( $8.6 \%$ in mean and $9.6 \%$ in women) $)^{2}$. Similar to other NCDs, CKD increases with age, rising to $20 \%$ in individuals in their 60 s to $35 \%$ among those above 70 years ${ }^{3}$. Between 1990 and 2013, the global years of life lost and years lived with disability (YLD) due to CKD increased by $90 \%$ and $49.5 \%$, respectively ${ }^{4}$. In some 
countries of Central and South America, CKD is now in the list of top 10 causes of death and disability $^{5}$. It has been suggested that the contribution of CKD to the overall disease burden is underestimated because of inaccurate cause of death reporting in those with CKD risk factors like diabetes ${ }^{6}$.

In 2010, approximately, 2.3 million people with end-stage kidney disease (ESKD) died prematurely as they did not have access to renal replacement therapy (RRT) ${ }^{7}$. A majority of these deaths took place in LMIC. In the next 15 years, the total number of people undergoing RRT will increase to 5.4 million, mostly in the emerging countries of Asia and Africa ${ }^{7}$. Similarly, about 13 million people develop AKI worldwide every year, over $85 \%$ of whom are in LMIC. Most of these cases are not identified in a timely manner, and fail to receive appropriate treatment ${ }^{8}$. Children and young adults develop AKI in association with diarrheal diseases, tropical infections, snake bites, poor obstetric care and consumption of toxic traditional medicines, suggesting absence of $\mathrm{PHI}$ that could have prevented $\mathrm{AKI}^{9}$.

\section{Barriers to provision of care for kidney disease in LMIC}

Cost of care

Kidney disease has a bi-directional relationship with poverty, implying that poverty predisposes to development of disease, and worsens the outcome of individuals with kidney disease. Care of patients with kidney disease has significant economic consequences on health systems and households. About $2-6 \%$ of the health-care expenditure in HICs is used to provide treatment for patients with ESKD even though they account for only $0 \cdot 1-0 \cdot 2 \%$ of the total population. Dialysis treatment costs accounted for $6 \cdot 3 \%$ of the Medicare budget in the USA in $2010,4 \cdot 1 \%$ of the total health-care budget in Japan in 1996, and about $1 \cdot 3 \%$ of all 
health spending in the UK ${ }^{10}$. In LMICs, the annual per patient cost for hemodialysis (HD) and peritoneal dialysis (PD) ranged from Int\$ 3,424 to Int\$ 42,785 and from Int\$ 7,974 to Int\$ 47,971 respectively ${ }^{11}$

In LMIC, healthcare costs are often met with out-of-pocket expenditure, leading to loss of household income. Each year about 100 million individuals spiral into poverty due to out of pocket costs for health care ${ }^{12}$. A recent study from India showed that spending for dialysis while awaiting kidney transplantation led to severe, moderate, and some financial crisis in $54 \%, 8 \%$, and $10 \%$ of families ${ }^{13}$. According to the Global Snapshot study of AKI conducted by the International Society of Nephrology, lack of resources and inability to afford therapy were common reasons to deny dialysis for AKI despite indication in several LMIC .

\section{Lack of trained human resources}

According to the WHO Global Health Observatory, $44 \%$ of all member states have less than 1 physician per 1000 population, and countries with the highest disease burden have the lowest number of healthcare workers ${ }^{14}$. This is reflected in the nephrology health workforce. There are less than 1 nephrologists per million population (pmp) in African and Southeast Asian countries, in contrast to 22 and $31 \mathrm{pmp}$ in North America and Western Europe ${ }^{15}$. Even within individual LMIC, there are disparities in the health workforce availability between rural and urban regions.

\section{System level issues with CKD management}

CKD screening is suboptimal globally, with $50 \%$ of people with CKD remaining undiagnosed in the community ${ }^{16}$. Management is compounded by delayed referrals, fragmented care, poor 
follow-up and referral pathways and inadequate focus on patient engagement and education ${ }^{17}$. These challenges are magnified several fold in LMICs. Health systems at primary care levels in most LMICs have been designed to focus on maternal and child health services and infectious diseases with minimal infrastructure and resources for chronic diseases. While some countries are slowly orienting their health systems to chronic disease management, the model of care in most LMICs is still a 'cure-based reactive model', rather than a 'care-based proactive healthcare model'.

\section{Public Health Interventions}

Public health interventions $(\mathrm{PHI})$ are measures applied to a population that have certain common characteristics, and can be directed to systems, communities or individuals. PHIs should be guided by an assessment of community health, consider broad determinants of health, and address all levels of prevention and practice. The individual components of PHIs can be broken down by the type of intervention and level of practice into several components, represented in the "Wheel of $\mathrm{PHI}{ }^{18}$ (Fig 1). A detailed discussion of the individual components of the wheel is outside the scope of this paper.

PHIs can be implemented at several levels, with varying degrees of impact. Elements of delivery go beyond the healthcare domain to the fundamentals of societal structure, which are the primary determinants of health. It is therefore useful to examine the $\mathrm{PHI}$ impact in terms of a 5 -tiered pyramid proposed by Friedan ${ }^{19}$. Table 1 shows the interventions that can be made at each of the 5 levels and the potential impact they might have on kidney health. The first two categories involve action at the population level, whereas the following 3 involve reaching individuals, which requires greater efforts. Reduction of poverty, deprivation and 
improved access to sanitation, transport, and access to basic services including healthcare will produce a major impact on all aspects of healthcare including kidney health. One can also change the context within which people make healthcare decisions, such that it becomes hard for people not to benefit from them - examples include elimination of environmental toxins, stronger regulation of indigenous medical systems, decreasing salt in packaged foods, banning smoking from public places, regulating the marketing of sugary drinks, improving working conditions, providing hydration to workers in hot areas and legalizing abortions. The third tier involves the interventions that bring long-term benefits, such as vaccinations, smoking cessation and establishment of good obstetric services. Ongoing clinical care involves development of special programs, such as screening and prophylaxis for kidney disease in appropriate situations, providing guideline-based care to those who screen positive, reducing non-adherence to therapy and institution of quality improvement programs. The final tier represents education and counselling by individual behaviour change, which require the most effort and resource mobilization and therefore are the least effective of all interventions. Successful implementation of PHIs requires synergy across all levels. The first two tiers have the biggest potential for improving health but are often not implemented because they require societal transformation through strong political will, and can be controversial. The tiers at the top are the least controversial but require large organisational effort in terms of the public health infrastructure.

\section{Current recommendations for CKD prevention and management}

Effectiveness of population level CKD prevention strategies have been shown in several countries, such as Taiwan, Chile, Uruguay and Cuba ${ }^{10}$. For widespread applicability in LMIC, however, such strategies need to be affordable and accessible to individuals, especially those 
from disadvantaged and remote communities. Comprehensive control of CKD would involve a collaborative model of care starting from screening and identification of early stage disease, continuing through to end of life support for those with advanced disease. Since early CKD is asymptomatic, screening individuals at high-risk and institution of preventive interventions is the only cost-effective method for case-detection and slowing of disease progression ${ }^{20}$. Population-based approaches such as maintenance of ideal body weight, physical activity, blood pressure lowering, and prevention and control of diabetes are likely to have a widespread positive impact, including the prevention of CKD. Much can be learnt from the tobacco control advocacy campaigns which raised public awareness and got industry to partner in the change. Similar changes are needed for salt restriction, sugar and calorie control to curtail the epidemic of chronic diseases including CKD. Infection control, in particular tropical infections that cause AKI and CKD, should be paramount in LMIC and requires a multipronged approach.

Since screening of entire communities is neither feasible nor affordable, screening should be limited to at-risk populations. Definition of at-risk populations remains a work in progress, however. Most global recommendations, developed from data in HIC, suggest screening those with known high blood pressure, diabetes or family history of CKD. Arguments that have been made for expanding the scope of screening in LMIC include a high burden of undiagnosed diabetes and hypertension in the community, and a high proportion of CKD due environmental factors, such as manual work in hot and humid environments (heat stress nephropathy), or local customs, such as consumption of traditional medicines ${ }^{21}$. However, proper cost-effectiveness studies and development of robust point of care diagnostic tools which can be used in communities are required before widespread screening can be 
recommended. ${ }^{21,22,23,24,25}$ In the interim, till cost effective point of care diagnostic tools are available proven cost-effective screening methods such as serum creatinine and proteinuria estimation ${ }^{26} 27$ followed by appropriate management should be incorporated at the primary health care level ${ }^{28}$.

The focus of secondary prevention is to slow the progression of CKD and its complications through lifestyle interventions, use of drugs that block the angiotensin pathway, control blood pressure and glycemia, and use of statins. This approach can be facilitated by use of a lowcost once-a-day fixed-dose combinations containing low-cost generic agents in the form of a 'polypill', a strategy that has been underused so far ${ }^{29}$.

\section{Health system strengthening using innovative solutions}

Health information systems in LMICs are still in their infancy, which contributes ongoing to inefficient health program planning ${ }^{30}$. Establishing accurate and reliable health information systems and disease registries including electronic medical records requires initial investment, but has the potential to increase health system efficiency, improve policy making and improve outcomes. Such systems should include inventory management and tracking. Ensuring reliable supplies of affordable medications through accurate forecasting and efficient supply chain management can remove barriers to care delivery ${ }^{31}$.

Novel healthcare financing mechanisms which do not rely on government funding, such as community health insurance schemes ${ }^{32}$ and microfinancing ${ }^{33}$ need to be considered in environments with high out-of-pocket healthcare expenditure. ${ }^{34}$ Unique ideas, such as crowdsourcing from high income earners channelled through non-government organisations 
such as the Kidney Foundation of Kerala in India is slowing gaining traction ${ }^{35,36}$. Other innovative solutions include linking physician reimbursements to patient insurance claims which tracks both hospital-based care and improvements in health outcomes for patients with chronic diseases ${ }^{37}$, shifting from fee-for-service to value based reimbursements and shared financial incentives for physicians and patients ${ }^{38}$.

Technology is changing the way in which healthcare is delivered ${ }^{39}$. Telehealth (communication between patient and health-care provider via phone, internet, and videoconference) has emerged as a potentially disruptive health delivery pathway, especially for chronic conditions ${ }^{40}$. Clinical data can be sent digitally in encrypted formats from the community using a mobile device (phone or tablet) and from the patient's home to health care providers through a secure network and appropriate management decisions can be made ${ }^{41}$. Two factor authentication and use of secure sockets layer for data transmission would ensure that the confidentiality and de-identification of demographic data to ensure privacy during these communication protocols. These processes can be augmented by point of care devices that connect with the handheld devices using secure wireless networks. Telemonitoring facilitates early remote identification of change in clinical condition and allows healthcare providers to modify treatment, thereby decreasing the number of hospital visits ${ }^{42}$. Technology also promotes self-management by patient education and empowerment ${ }^{43,44}$, and improves communication with health professionals $s^{45} 46,4748$, helps provide information in understandable bytes, which can be delivered at regular intervals. Furthermore, integration into health information system will permit tracking and faster realtime identification of problems and gaps that can be addressed. 
Physician scarcity in LMIC has led to development of alternate evidence based models of care 49. Community health workers ( $\mathrm{CHW}$ ) have been trained to standardize maternal care using simple checklists, and brought about major improvements in delivery-related complications and mortality ${ }^{50}$ in LMIC Similar models are being explored for cardiovascular disease ${ }^{51-53}$, diabetes ${ }^{54,55}$ and depressive disorders ${ }^{56}$. Use of CHWs to screen individuals at risk of CKD using evidence-based decision support tools, and referring them to physicians when needed would promote early detection and management of $\mathrm{CKD}^{57,5859}$. Collaboration and training of traditional healers, who are trusted by communities, in this may aid in this effort ${ }^{60}$.

It is necessary to develop standardised algorithms/pathways based on evidence-based guidelines after appropriate adaptation (see below) for CKD prevention and management in the primary care setting with clear decision points, checklists, and levels of referral according to the local healthcare infrastructure.

Integrating care at the primary care level by promoting opportunistic screening during routine check-ups such as immunization or appointments for other indications using such tools would increase operational efficiencies, improve quality and provide holistic care. At secondary and tertiary health facility levels, nurses can be trained to work alongside nephrologists and provide lifestyle education and follow-up advice. Physician assistants and nurse practitioners can also be trained to provide more advanced care, such as vascular access creation and care, and prescription and management of dialysis treatments ${ }^{61,62}$. Where available, dietitians and pharmacists can strengthen the multidisciplinary teams ${ }^{54,55}$. The WHO guidelines for taskshifting highlight the importance of quality assurance mechanisms using standardised training, supervision, certification and assessment ${ }^{63}$. 
This effort should be complemented by development of curricula and toolkits adapted to local needs. Instructions on standardized training, competency and skills assessment with requirements for certification and mandatory recertification are helpful. Institution of quality parameters and performance incentives have been shown to improve outcomes. The quality and structure of incentives, however, may be different for public providers and private practitioners. Such public health interventions have been shown to reduce the risk of decline in eGFR and/or death ${ }^{57}$.

\section{Engaging policymakers: data as an enabler for public health interventions}

Despite the compelling data on disease burden and the consequences, kidney disease has not found resonance with the policymakers in many LMICs, and is missing from NCD prevention and control strategies. An important reason is lack of country-specific data on the consequences of undiagnosed and untreated CKD - expressed preferably in the form of numbers of years lost due to premature deaths and disability, and health-economic analysis of the consequences of untreated kidney disease.

Availability of good quality data, disaggregated in terms of gender, geography and special populations, would help inform policy decisions, prioritisation of interventions and tracking of program effectiveness. Several reviews and meta-analyses on the burden of AKI and CKD are available ${ }^{64,65}$, but most highlight lack of data from LMIC. Renal registries have played a vital role as a public health surveillance system, and informed shaping of national kidney disease programs throughout the developed world. A recent review, highlighted the lack of renal disease registries in LMICS of Africa and Asia, covering about two-third of the world 
population ${ }^{66}$. Some meta-analyses have therefore extrapolated data from the developed world to estimate disease burden in emerging countries ${ }^{67}$.

Lack of reliable data on disease burden, treatment practices and outcomes constitute a major barrier to formulation of appropriately directed PHI. Efforts have been started to develop globally applicable frameworks for collection of essential data, using open source IT solutions. This affords a low-cost alternative to traditional paper based data collection formats, with the added advantage of allowing standardised international comparisons. Examples include Global AKI snapshot ${ }^{68}$, the Global Kidney Health Atlas initiated by the International Society of Nephrology and the Dialysis Outcomes Study in India $69,7068,71$.

\section{Engaging policymakers: Beyond data}

Local nephrology community, with the assistance of global experts, and facilitated by organisations like the International Society of Nephrology, Kidney Disease: Improving Global Outcomes (KDIGO) and regional branches of the WHO should develop toolkits to demonstrate the benefits of CKD detection and treatment programs; estimate costs of care for CKD patients; and demonstration of cost-effectiveness for screening of at-risk populations. Knowledge of the number of people that would need to be treated to save each DALY and the savings that would accrue to the healthcare system from prevention efforts would help to convince policymakers of the importance of targeting CKD in proposed NCD management programs as well as reducing the preventable deaths associated with AKI particularly those in women of childbearing age group and children through concerted efforts as those initiated by ISN 0 by 25 initiative . 
Initial analysis of disease burden and health economics should be followed by examination of public policy alternatives and evaluation of cost-benefit of each of these alternatives. For example - the competing scenarios in the case of CKD could include early detection and prevention of disease progression, versus allowing disease to progress and then providing expensive treatment like dialysis, or an offering no treatment. These choices should be examined from financial, ethical, legal and political standpoints.

Once the local burden of kidney disease is acknowledged as a priority and action steps to address the public health problem have been identified, implementation requires examination of available resources (health workforce, infrastructure, and training), securing buy-in from all stakeholders, resolution of administrative conflicts, and development of qualitative and quantitative outcome indicators. Countries will need to pilot some of these initiatives to understand the key challenges and facilitators for the intervention before rolling it out to the entire country.

\section{Models of care for prevention and management - an example}

An example of such disruptive innovation is Systematic Appraisal Referral and Treatment system (SMARTHealth) currently being evaluated in rural India ${ }^{72}$. SMARTHealth is a multifaceted intervention involving capacity strengthening of primary care physicians and CHWs through the use of a mobile device-based clinical decision support system which utilises a guideline based screening and management algorithm. Figure 2 shows the workflow of SMARTHealth. Briefly, CHWs screen individuals in the community using the SMARTHealth application, loaded on a tablet device. This information is uploaded over 2G/3G network to a secure, cloud-based, electronic medical record system developed using open source 
software. CHWs can make electronic referrals to primary care physicians. On their part, physicians can communicate the diagnosis and management plan to the CHWs via their devices. This innovative model has been able to address several existing system level barriers such as workforce shortage via task-shifting, improvement in quality assurance through provision of uniform evidence-based clinical decision support, development of electronic medical records, and development of a reliable community-based disease registry. This model has provision for disseminating tailored text or voice messages to promote healthy behaviour and treatment adherence overcoming illiteracy /language barriers. Such a model of care lends itself to the management of diseases with shared risk-factors and overlapping management plans. However, up-stream challenges such as shortage of essential medicines, inadequate remuneration of healthcare providers and high turnover of $\mathrm{CHWs}$ due to lack of job security are potential threats ${ }^{48}$. While information technology and data driven approaches to monitoring increase efficiency, they could pose a threat to patient privacy (but no more than other EMRs) and create a perception amongst healthcare workers that they are being constantly tracked. This however could be overcoming by incorporating performance dashboards that are linked to their incentives as part of their renumeration.

\section{Knowledge gaps and research recommendations}

$\mathrm{PHI}$ within a context of limited resources mandates that the decision-makers invest in proven, cost-effective solutions. Evidence is needed to show effectiveness of interventions as a rationale for choosing a particular course of action, and to justify the allocation of funding and resources. In addition to data and information systems, evidence-based public health practice also requires appropriate use of behavioural science theory and program planning models. 
While LMICs can learn and adapt lessons in the prevention and control of CKD from HICs, several factors inherent to LMICs require new research and further investment. There is a need to establish cohorts to gather knowledge about risk-factors unique to LMICs $21,22,24,73$ that will help appropriate tailoring of screening guidelines. Research is also needed to evaluate novel affordable and scalable models of care which involve task-sharing, innovative financing mechanisms, and harnessing technology for screening, diagnosis, treatment and self-management. In addition to the tools described above, development of cheap point of care diagnostics would allow bringing preventive care to the population, as opposed to the current model where the onus is on the person to approach the health system. Future studies should also evaluate culturally appropriate methods of communication about the risks and benefits of various management choices so that patients can make informed decisions at all levels of care $^{74}$.

\section{Conclusions}

CKD is a neglected chronic disease which poses a significant challenge to the health system, especially in LMICs where the disease burden is not defined and health systems are not geared for prevention or treatment of chronic diseases. An important first step is to establish accurate and reliable health information systems and disease registries to capture the true burden of disease. Preventive strategies should include broad PHIs such as clean drinking water, vaccination, infection control as well as calorie restriction and low-salt diet to prevent high blood pressure and diabetes. System level changes are needed to ensure that countries have adequately trained staff to screen, diagnose and manage individuals using evidencebased and cost-effective strategies. Such a model of care would promote awareness in the 
population, help improve access to good quality primary care, promote early diagnosis and treatment, and thereby lead to reduced morbidity and premature mortality. Political will is needed to address challenges such as improving medication procurement and storage, encouraging multidisciplinary models of care by better remuneration policies for the workforce and providing universal health coverage to protect vulnerable populations from financial hardships. System level change is needed to prevent and manage CKD in the community if the sustainable development goals of reducing pre-mature mortality from NCDs by 2030 are to be attained. 


\section{References}

1. Schoolwerth AC, Engelgau MM, Hostetter TH, et al. Chronic kidney disease: a public health problem that needs a public health action plan. Prev Chronic Dis. 2006;3.

2. Mills $K T, X u Y$, Zhang $W$, et al. A systematic analysis of worldwide population-based data on the global burden of chronic kidney disease in 2010. Kidney international. Nov 2015;88(5):950-957.

3. Eckardt KU, Coresh J, Devuyst O, et al. Evolving importance of kidney disease: from subspecialty to global health burden. Lancet. Jul 13 2013;382(9887):158-169.

4. GBD 2013 Mortality and Causes of Death Collaborators. Global, regional, and national age-sex specific all-cause and cause-specific mortality for 240 causes of death, 1990-2013: a systematic analysis for the Global Burden of Disease Study 2013. Lancet. Jan 10 2015;385(9963):117-171.

5. Lozano R, Naghavi M, Foreman K, Lim S, Shibuya K, Aboyans V. Global and regional mortality from 235 causes of death for 20 age groups in 1990 and 2010: a systematic analysis for the Global Burden of Disease Study 2010. Lancet. 2012;380.

6. Rampatige R, Mikkelsen L, Hernandez B, Riley I, Lopez AD. Hospital cause-of-death statistics: what should we make of them? Bulletin of the WHO. 2014;92(3):http://dx.doi.org/10.2471/BLT.2413.134106.

7. Liyanage $T$, Ninomiya $T$, Jha $V$, et al. Worldwide access to treatment for end-stage kidney disease: a systematic review. Lancet. May 16 2015;385(9981):1975-1982.

8. Mehta RL, Burdmann EA, Cerda J, et al. Recognition and management of acute kidney injury in the International Society of Nephrology 0by25 Global Snapshot: a multinational cross-sectional study. Lancet. May 14 2016;387(10032):2017-2025. 
9. Jha V, Parameswaran S. Community-acquired acute kidney injury in tropical countries. Nature reviews. Nephrology. May 2013;9(5):278-290.

10. Jha V, Garcia-Garcia G, Iseki K, et al. Chronic kidney disease: global dimension and perspectives. Lancet. Jul 20 2013;382(9888):260-272.

11. Mushi L, Marschall P, Fleßa S. The cost of dialysis in low and middle-income countries: a systematic review. BMC Health Services Research. 2015;15(1):1-10.

12. World Health Association. The World Health Report 2010-Health Systems Financing: the Path to Universal Coverage.: World Health Organisation;2010.

13. Ramachandran R, Jha V. Kidney Transplantation Is Associated with Catastrophic Out of Pocket Expenditure in India. PLoS ONE. 2013;8(7):e67812.

14. World Health Organisation. Density of physicians (total number per 1000 population, latest available year). Global Health Observatory Data http://www.who.int/gho/health_workforce/physicians_density_text/en/.Accessed 13.5.16, 2016.

15. Sharif MU, Elsayed ME, Stack AG. The global nephrology workforce: emerging threats and potential solutions! Clinical Kidney Journal. 2016;9(1):11-22.

16. Chen T, Harris DC. Challenges of chronic kidney disease prevention. Medical Journal of Australia. 2015;203(5):209-210.

17. Fishbane S, Hazzan AD, Halinski C, Mathew AT. Challenges and opportunities in latestage chronic kidney disease. Clinical Kidney Journal. December 2, 20142014.

18. Keller LO, Strohschein S, Lia-Hoagberg B, Schaffer MA. Population-based public health interventions: practice-based and evidence-supported. Part I. Public health nursing (Boston, Mass.). Sep-Oct 2004;21(5):453-468. 
19. Frieden TR. A Framework for Public Health Action: The Health Impact Pyramid. American Journal of Public Health. 12/08/accepted 2010;100(4):590-595.

20. Vassalotti JA, Fox CH, Becker BN. Risk Factors and Screening for Chronic Kidney\&\#xa0;Disease. Advances in Chronic Kidney Disease.17(3):237-245.

21. Glaser J, Lemery J, Rajagopalan B, et al. Climate Change and the Emergent Epidemic of CKD from Heat Stress in Rural Communities: The Case for Heat Stress Nephropathy. Clinical Journal of the American Society of Nephrology. May 5, 2016 2016.

22. Gooneratne IK, Ranaweera AK, Liyanarachchi NP, Gunawardane N, Lanerolle RD. Epidemiology of chronic kidney disease in a Sri Lankan population. International journal of diabetes in developing countries. Apr 2008;28(2):60-64.

23. Weaver VM, Fadrowski JJ, Jaar BG. Global dimensions of chronic kidney disease of unknown etiology (CKDu): a modern era environmental and/or occupational nephropathy? BMC Nephrology. 2015;16(1):1-8.

24. Correa-Rotter R, Wesseling C, Johnson RJ. CKD of unknown origin in Central America: the case for a Mesoamerican nephropathy. American journal of kidney diseases : the official journal of the National Kidney Foundation. Mar 2014;63(3):506-520.

25. Jayasinghe S. Chronic kidney disease of unknown etiology should be renamed chronic agrochemical nephropathy. MEDICC Review. 2014;16:72-74.

26. Bochud M. On the rationale of population screening for chronic kidney disease: a public health perspective. Public Health Reviews. 2015;36(1):1-11.

27. Howard K, White S, Salkeld G, et al. Cost-effectiveness of screening and optimal management for diabetes, hypertension, and chronic kidney disease: a modeled 
analysis. Value in health : the journal of the International Society for

Pharmacoeconomics and Outcomes Research. Mar-Apr 2010;13(2):196-208.

28. Manns B, Hemmelgarn B, Tonelli M, et al. Population based screening for chronic kidney disease: cost effectiveness study. The BMJ. 11/08

09/02/accepted 2010;341:c5869.

29. Gaziano TA, Galea G, Reddy KS. Scaling up interventions for chronic disease prevention: the evidence. Lancet. Dec 8 2007;370(9603):1939-1946.

30. Ene-lordache B, Perico N, Bikbov B, et al. Chronic kidney disease and cardiovascular risk in six regions of the world (ISN-KDDC): a cross-sectional study. The Lancet Global Health.4(5):e307-e319.

31. Maher D, Ford N, Unwin N. Priorities for developing countries in the global response to non-communicable diseases. Globalization and Health. 2012;8(1):1-8.

32. Donfouet HPP, Mahieu P-A. Community-based health insurance and social capital: a review. Health Economics Review. 2012;2(1):1-5.

33. Leatherman S, Dunford C. Linking health to microfinance to reduce poverty. Bull World Health Organ. 2010;88:470-471.

34. World Health Organisation. World Health Statistics 2007. Chapter 10. Health expenditure: meeting needs? 2007.

35. Kidney Foundation Kerala. Care for your kidneys. http://www.kidneyfoundationkerala.com/public/index.php. Accessed 16 June, 2016.

36. Public Health Foundation of India. Moving Towards Universal Health Coverage in Kerala, Piloting in the Districts of Malappuram and Palakkad. PHFI / Govt of Kerala;2016. 
37. Steele GD. A proven new model for reimbursing physicians. NEJM, Havard Business Review. 2015.

38. Asch DA, Troxel AB, Stewart WF, et al. Effect of financial incentives to physicians, patients, or both on lipid levels: A randomized clinical trial. JAMA : the journal of the American Medical Association. 2015;314(18):1926-1935.

39. Hameed SS, Rawal I, Soni D, Ajay VS, Goenka S, Prabhakaran D. Technology for Diagnosis, Treatment, and Prevention of Cardiometabolic Disease in India. Progress in Cardiovascular Diseases.

40. Neubeck Lis, Redfern J, Fernandez Ritin, Briffa Tom, Bauman Adrian, Freedman Saul Ben. Telehealth interventions for the secondary prevention of coronary heart disease: a systematic review. European Journal of Cardiovascular Prevention \& Rehabilitation. June 1, 2009 2009;16(3):281-289.

41. Martin-Lesende Inaki, Orruno E, Bilbao Amaia, et al. Impact of telemonitoring home care patients with heart failure or chronic lung disease from primary care on healthcare resource use (the TELBIL study randomised controlled trial). BMC Health Services Research. 2013;13(1):118.

42. Chaudhry Sarwat I, Mattera Jennifer A, Curtis Jeptha P, et al. Telemonitoring in Patients with Heart Failure. New England Journal of Medicine. 2010;363(24):23012309.

43. Chow CK, Redfern J, Hillis GS, et al. Effect of lifestyle-focused text messaging on risk factor modification in patients with coronary heart disease: A randomized clinical trial. JAMA : the journal of the American Medical Association. 2015;314(12):12551263. 
44. Redfern J, Usherwood T, Harris MF, et al. A randomised controlled trial of a consumer-focused e-health strategy for cardiovascular risk management in primary care: the Consumer Navigation of Electronic Cardiovascular Tools (CONNECT) study protocol. BMJ open. February 1, 2014 2014;4(2).

45. LaMonte MP, Bahouth MN, Hu P, et al. Telemedicine for Acute Stroke: Triumphs and Pitfalls. Stroke. March 1, 2003 2003;34(3):725-728.

46. Peiris D, Usherwood T, Panaretto K, et al. The Treatment of cardiovascular Risk in Primary care using Electronic Decision supOrt (TORPEDO) study-intervention development and protocol for a cluster randomised, controlled trial of an electronic decision support and quality improvement intervention in Australian primary healthcare. BMJ open. 2012;2(6).

47. Peiris DP, Joshi R, Webster RJ, et al. An electronic clinical decision support tool to assist primary care providers in cardiovascular disease risk management: development and mixed methods evaluation. J Med Internet Res. 2009;11(4):e51.

48. Praveen D, Patel A, Raghu A, et al. SMARTHealth India: Development and Field Evaluation of a Mobile Clinical Decision Support System for Cardiovascular Diseases in Rural India. JMIR Mhealth Uhealth. 2014;2(4):e54.

49. Mazzuchi N, Schwedt E, Sola L, Gonzalez C, Ferreiro A. Risk factors and prevention of end stage renal disease in uruguay. Ren Fail. 2006;28(8):617-625.

50. Gilmore B, McAuliffe E. Effectiveness of community health workers delivering preventive interventions for maternal and child health in low- and middle-income countries: a systematic review. BMC public health. 2013;13(1):1-14. 
51. Nyonator FK, Awoonor-Williams JK, Phillips JF. The Ghana community-based health planning and services initiative for scaling up service delivery innovation. Health Policy Plan. 2005;20.

52. Joshi R, Alim M, Kengne AP, et al. Task Shifting for Non-Communicable Disease Management in Low and Middle Income Countries ? A Systematic Review. PLoS ONE. 2014;9(8):e103754.

53. Xavier D, Gupta R, Kamath D, et al. Community health worker-based intervention for adherence to drugs and lifestyle change after acute coronary syndrome: a multicentre, open, randomised controlled trial. The Lancet Diabetes \& Endocrinology.4(3):244-253.

54. Hatah E, Braund R, Tordoff J, Duffull SB. A systematic review and meta-analysis of pharmacist-led fee-for-services medication review. British journal of clinical pharmacology. Jan 2014;77(1):102-115.

55. Morgado MP, Morgado SR, Mendes LC, Pereira L, Castelo-Branco M. Pharmacist interventions to enhance blood pressure control and adherence to antihypertensive therapy: Review and meta-analysis. American journal of health-system pharmacy : AJHP : official journal of the American Society of Health-System Pharmacists. Feb 1 2011;68(3):241-253.

56. Patel V, Weiss HA, Chowdhary N, et al. Effectiveness of an intervention led by lay health counsellors for depressive and anxiety disorders in primary care in Goa, India (MANAS): a cluster randomised controlled trial. The Lancet.376(9758):2086-2095.

57. Mani MK. Experience with a program for prevention of chronic renal failure in india. Kidney Int Suppl. 2005;94(94):S75-78.

58. Hoy WE, Kondalsamy Chennakesavan S, Katz I, 2005;68:S76-S82. AcdopfAAcKI. 
59. Jafar TH, Allen JC, Jehan I, et al. Health education and general practitioner training in hypertension management: Long term effects on kidney function. CJASN. 2016;May:doi: 10.2215/CJN.05300515.

60. Viney $\mathrm{K}$, Johnson $\mathrm{P}$, Tagaro $\mathrm{M}$, et al. Traditional healers and the potential for collaboration with the national tuberculosis programme in Vanuatu: results from a mixed methods study. BMC public health. 2014;14(1):1-9.

61. Price CA, Paganini EP. Debate: Should Nurses Have a Larger Role in the Outpatient Dialysis Setting Than They Currently Do? Seminars in Dialysis. 1999;12(5):359-362.

62. Bennett PN. Satellite dialysis nursing: technology, caring and power. Journal of Advanced Nursing. 2011;67(1):149-157.

63. World Health Organisation. Task shifting: global recommendations and guidelines. Geneva: World Health Organisation;2008.

64. Tonelli M, Wiebe N, Culleton B, et al. Chronic kidney disease and mortality risk: a systematic review. J Am Soc Nephrol. Jul 2006;17(7):2034-2047.

65. Zhang QL, Rothenbacher D. Prevalence of chronic kidney disease in populationbased studies: systematic review. BMC public health. 2008;8:117.

66. Liu FX, Rutherford P, Smoyer-Tomic K, Prichard S, Laplante S. A global overview of renal registries: a systematic review. BMC Nephrology. 2015;16(1):1-10.

67. Thomas MC, Cooper ME, Zimmet P. Changing epidemiology of type 2 diabetes mellitus and associated chronic kidney disease. Nat Rev Nephrol. 02//print 2016;12(2):73-81.

68. Mehta RL, Burdmann EA, Cerdá J, et al. Recognition and management of acute kidney injury in the International Society of Nephrology 0by25 Global Snapshot: a multinational cross-sectional study. The Lancet.387(10032):2017-2025. 
69. Jha V, John O, Joshi R, et al. Dialysis outcomes in India: a pilot study. Nephrology (Carlton). May 2015;20(5):329-334.

70. Robinson BM, Bieber B, Pisoni RL, Port FK. Dialysis Outcomes and Practice Patterns Study (DOPPS): its strengths, limitations, and role in informing practices and policies. Clin J Am Soc Nephrol. Nov 2012;7(11):1897-1905.

71. Nephrology ISo. 0 by 25 initiative. http://www.theisn.org/initiatives/0by25. Accessed 23rd May, 2016, 2016.

72. Praveen D, Patel A, McMahon S, et al. A multifaceted strategy using mobile technology to assist rural primary healthcare doctors and frontline health workers in cardiovascular disease risk management: protocol for the SMARTHealth India cluster randomised controlled trial. Implementation science : IS. 2013;8:137.

73. Sabath E, Robles-Osorio ML. Renal health and the environment: heavy metal nephrotoxicity. Nefrologia : publicacion oficial de la Sociedad Espanola Nefrologia. May 14 2012;32(3):279-286.

74. Tonelli M, Riella M. Chronic kidney disease and the aging population. Nephrology Dialysis Transplantation. February 1, 2014 2014;29(2):221-224. 
Tables and Figures

Figure 1: Wheel of Public Health Intervention

Figure 2: Key features of SMARThealth India

Table 1: Levels of Public health interventions, specific steps and the potential impact on kidney health

Table 2: Barriers and enablers of CKD prevention and management 
Table 1: Levels of Public health interventions, specific steps and the potential impact on kidney health

\begin{tabular}{|c|c|c|c|}
\hline Elements & Specific steps & Impact on kidney health & Comments \\
\hline $\begin{array}{l}\text { Socioeconomic } \\
\text { factors }\end{array}$ & $\begin{array}{l}\text { - Improved livelihood, education and } \\
\text { sanitation } \\
\text { - Universal access to timely affordable } \\
\text { healthcare }\end{array}$ & $\begin{array}{l}\text { - Overall improvement in health } \\
\text { - Reduced NCD burden }\end{array}$ & $\begin{array}{l}\text { - Requires political will } \\
\text { - Linked to overall development and } \\
\text { economic growth over long term } \\
\text { - Radical redesign of health systems } \\
\text { required }\end{array}$ \\
\hline $\begin{array}{l}\text { Changing the } \\
\text { context to } \\
\text { make default } \\
\text { decisions } \\
\text { healthy }\end{array}$ & $\begin{array}{l}\text { - } \text { Reducing salt in packaged foods, } \\
\text { - Higher taxation for tobacco, sweetened } \\
\text { beverages, and processed foods } \\
\text { - } \text { Regulate OTC/indigenous medicine use } \\
\text { - Mandate protective clothing/footwear in } \\
\text { - } \text { certain occupations (outdoor exposure) } \\
\text { legalization of abortions } \\
\text { - Widespread ORS availability }\end{array}$ & $\begin{array}{l}\text { - Reduction in kidney disease risk } \\
\text { factors (hypertension, diabetes, } \\
\text { metabolic syndrome) } \\
\text { - Reduction in CKDnT } \\
\text { - Slowed progression of CKD } \\
\text { - Reduction in occupation- } \\
\text { - } \text { related CKD and AKI } \\
\text { - Reduction in obstetric AKI }\end{array}$ & $\begin{array}{l}\text { - } \quad \text { Requires political will } \\
\text { - Likely opposition from special } \\
\text { interest groups and Industry lobby }\end{array}$ \\
\hline $\begin{array}{l}\text { Clinical } \\
\text { interventions }\end{array}$ & $\begin{array}{l}\text { - Treatment of risk factors and } \\
\text { predisposing conditions } \\
\text { - Measures to improve adherence to } \\
\text { treatment }\end{array}$ & $\begin{array}{l}\text { - Reduction in CKD development } \\
\text { and progression } \\
\text { - Improvement in obstetric AKI } \\
\text { through tracking outcomes }\end{array}$ & $\begin{array}{l}\text { - Needs manpower and resources } \\
\text { - Ensuring a continuum of care } \\
\text { - Effective health information } \\
\text { systems deployment }\end{array}$ \\
\hline $\begin{array}{l}\text { Counselling } \\
\text { and education }\end{array}$ & $\begin{array}{l}\text { - Increase kidney disease awareness } \\
\text { - Dietary counselling } \\
\text { - Increase physical activity }\end{array}$ & $\begin{array}{l}\text { - Can slow CKD progression and } \\
\text { prevent AKI in certain } \\
\text { situations }\end{array}$ & $\begin{array}{l}\text { - Least effective } \\
\text { - Requires civil society engagement } \\
\text { and ownership }\end{array}$ \\
\hline
\end{tabular}


NCD: non-communicable disease, CKD: chronic kidney disease, AKI: acute kidney injury; CKDnT: CKD of non-traditional causes; ORS: oral rehydration solution; OTC: over the counter, VPD : vaccine preventable diseases 
Table 2: Barriers and enablers for CKD prevention and management in LMIC

\begin{tabular}{|c|c|c|c|c|}
\hline Problem & Barrier & Enabler & System level change & Research needs \\
\hline \multirow{2}{*}{ 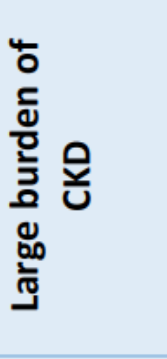 } & $\begin{array}{l}\text { High prevalence of LBW } \\
\text { babies, infections }\end{array}$ & $\begin{array}{l}\text { Antenatal care, infection } \\
\text { control, immunisation }\end{array}$ & $\begin{array}{l}\text { Integrate health care delivery into } \\
\text { primary care }\end{array}$ & $\begin{array}{l}\text { Evaluation of impact of } \\
\text { current } \mathrm{PHI} \text { such as } \\
\text { nutrition supplementation, } \\
\text { vaccination, child health }\end{array}$ \\
\hline & High rates of high $B P, D M$ & $\begin{array}{l}\text { Population based strategies } \\
\text { i.e. salt/sugar restriction, } \\
\text { tobacco control }\end{array}$ & $\begin{array}{l}\text { Industry partnership for long lasting } \\
\text { change }\end{array}$ & $\begin{array}{l}\text { Novel models of } \\
\text { partnerships }\end{array}$ \\
\hline \multirow{4}{*}{ 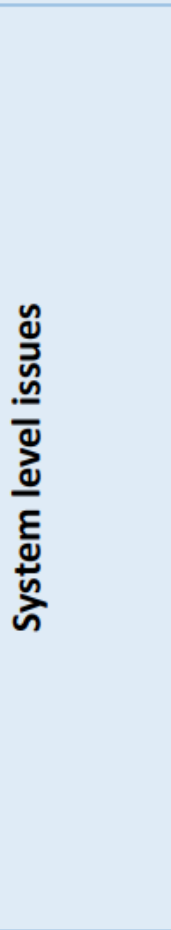 } & $\begin{array}{l}\text { Inadequate medicine } \\
\text { supply }\end{array}$ & $\begin{array}{l}\text { Availability of generic } \\
\text { medicines }\end{array}$ & $\begin{array}{l}\text { Improve health information systems to } \\
\text { ensure streamlined procurement and } \\
\text { supply }\end{array}$ & $\begin{array}{l}\text { Research to evaluate } \\
\text { generic fixed-dose polypills }\end{array}$ \\
\hline & Lack of nephrologists & $\begin{array}{l}\text { Active community health } \\
\text { workers cadre, traditional } \\
\text { healers }\end{array}$ & $\begin{array}{l}\text { Train CHWs to screen, refer, educate } \\
\text { individuals and prescribe from a } \\
\text { restricted medicine list } \\
\text { Train non-traditional physicians to } \\
\text { screen and manage patients with AKI } \\
\text { and CKD }\end{array}$ & $\begin{array}{l}\text { Develop and evaluate the } \\
\text { effectiveness of } \mathrm{CHW} \text { based } \\
\text { care. } \\
\text { Evaluate quality of care and } \\
\text { incentivise accordingly }\end{array}$ \\
\hline & $\begin{array}{l}\text { Inadequate health systems } \\
\text { response to kidney care } \\
\text { and chronic disease } \\
\text { delivery }\end{array}$ & $\begin{array}{l}\text { Political will to change health } \\
\text { policy }\end{array}$ & $\begin{array}{l}\text { Reorienting health systems from 'cure- } \\
\text { based reactive' model to 'care-based } \\
\text { proactive' model }\end{array}$ & $\begin{array}{l}\text { Role of strengthening non } \\
\text { physician healthcare } \\
\text { workers in improving access } \\
\text { to care }\end{array}$ \\
\hline & $\begin{array}{l}\text { Lack of incentives for } \\
\text { disease prevention }\end{array}$ & & $\begin{array}{l}\text { Adopt innovative strategies to } \\
\text { incentivise physicians for disease }\end{array}$ & $\begin{array}{l}\text { Evaluate prevention based } \\
\text { incentives }\end{array}$ \\
\hline
\end{tabular}




\begin{tabular}{|c|c|c|c|c|}
\hline & & & $\begin{array}{l}\text { prevention by linking insurance } \\
\text { schemes }\end{array}$ & \\
\hline & High cost of care & $\begin{array}{l}\text { Innovative financing } \\
\text { mechanisms }\end{array}$ & Adopting universal health coverage & $\begin{array}{l}\text { Research innovative } \\
\text { financing mechanisms }\end{array}$ \\
\hline \multirow{3}{*}{ 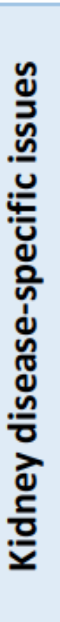 } & $\begin{array}{l}\text { Omission of kidney disease } \\
\text { screening and management } \\
\text { in curricula }\end{array}$ & Education reforms & $\begin{array}{l}\text { Development of guidelines which } \\
\text { incorporate LMIC centric guidelines for } \\
\text { screening and management }\end{array}$ & $\begin{array}{l}\text { Review implementation via } \\
\text { monitoring and evaluation }\end{array}$ \\
\hline & $\begin{array}{l}\text { Inadequate understanding } \\
\text { of risk factors for CKD } \\
\text { development and/or } \\
\text { progression }\end{array}$ & $\begin{array}{l}\text { Increasing awareness of } \\
\text { NCDs } \\
\text { National NCD prevention } \\
\text { programs }\end{array}$ & $\begin{array}{l}\text { Public education } \\
\text { Community engagement }\end{array}$ & $\begin{array}{l}\text { Establish cohort studies in } \\
\text { LMICs to gain a better } \\
\text { understanding of CKD risk } \\
\text { factors }\end{array}$ \\
\hline & $\begin{array}{l}\text { Delayed diagnosis, late } \\
\text { presentation with } \\
\text { advanced disease and } \\
\text { complication }\end{array}$ & $\begin{array}{l}\text { Improved communication and } \\
\text { transport }\end{array}$ & $\begin{array}{l}\text { Health education } \\
\text { Public service messaging }\end{array}$ & $\begin{array}{l}\text { Role of Social Media } \\
\text { engagement in behaviour } \\
\text { change in NCDs / CKD }\end{array}$ \\
\hline
\end{tabular}


Figure 1: Wheel of Public Health Intervention

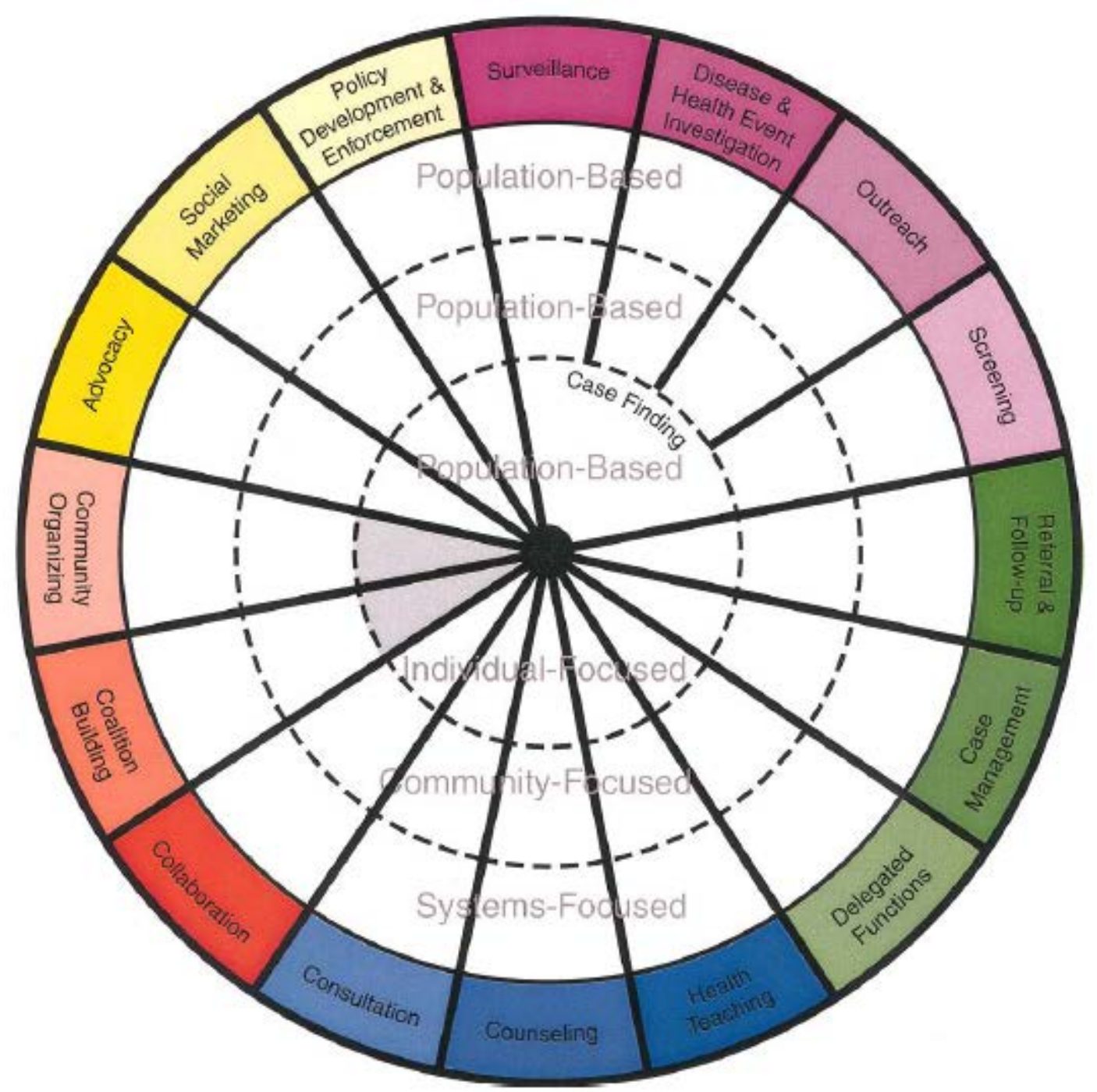

33 | P a g e 
Figure 2: Key features of SmartHealth India

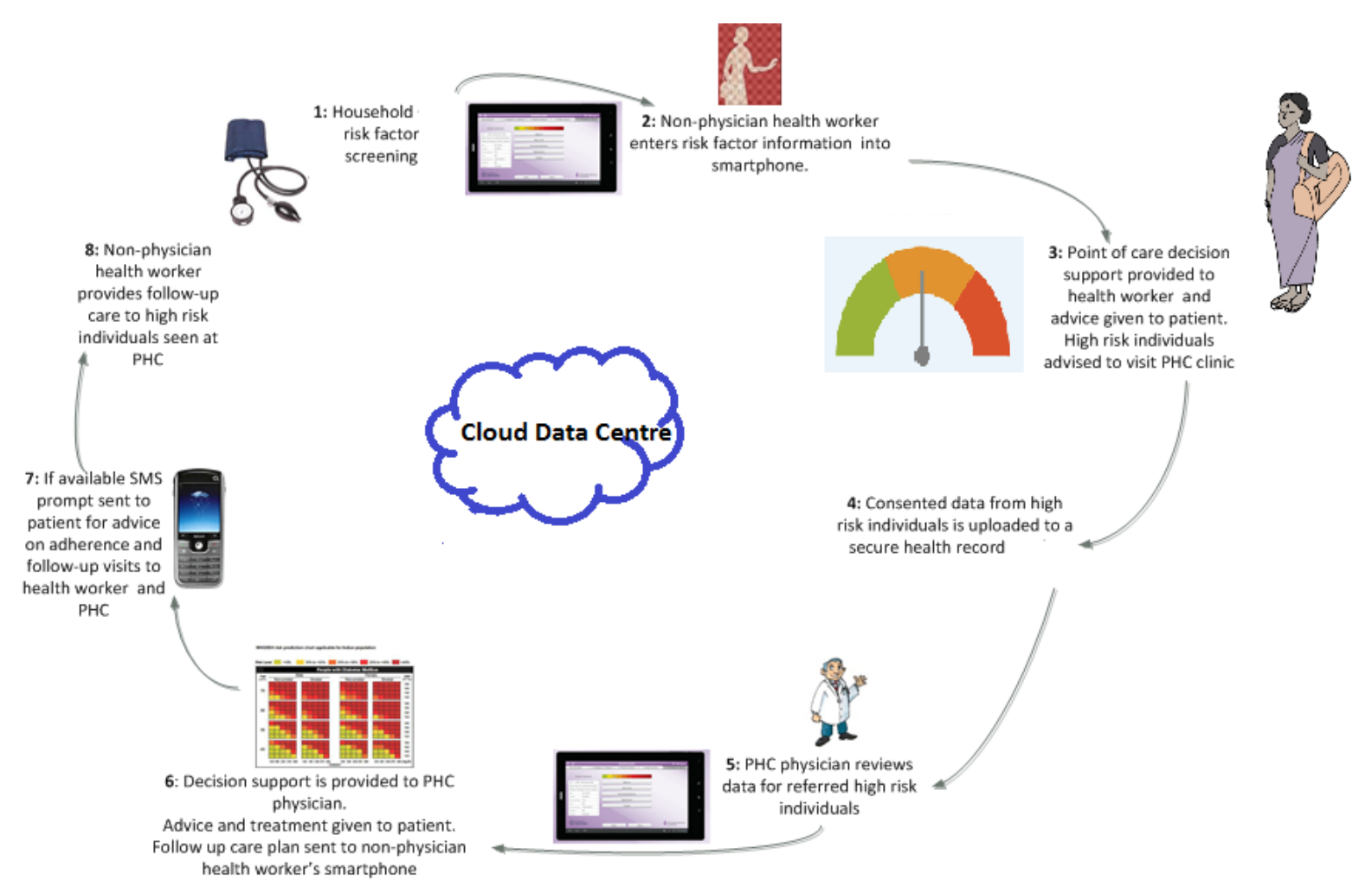

34 P a g e 